\title{
An Empirical Examination of Subject Headings for Women's Studies Core Materials
}

\author{
Kristin H. Gerhard, Mila C. Su, and Charlotte C. \\ Rubens
}

\begin{abstract}
The ACRL Women's Studies Section Technical Services Committee investigated the assignment of subject headings to core works in women's studies. Annotations for the works were compared with subject headings on OCLC cataloging copy, mainly created by the Library of Congress. Inadequacies were identified and traced to three sources: inadequacy of terminology, the complexities of assigning headings in interdisciplinary and/or emerging fields, and standard cataloging practices. Recommendations for amelioration of these problems are made.
\end{abstract}

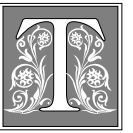

he Technical Services Committee of the ACRL's Women's Studies Section focuses on issues related to access and other relevant practices in areas such as acquisitions, cataloging, classification, and preservation. Membership on the committee includes both technical services and reference librarians. In 1992, the committee compiled a bibliography on issues in subject access to women's studies materials. There was a great deal of important enumerative and impressionistic work describing deficiencies in subject access to women's studies literature, in- cluding calls and suggestions for improved access. However, no empirical study had been published that identified specific changes needed to improve basic access to the core literature in the field. The study described below, designed and carried out by the group, seeks to remedy this situation.

Second, there has been no systematic evaluation of cataloger knowledge in terms of appropriate applications of women's studies subject headings. This study gives a preliminary glimpse into cataloger knowledge and identifies some fruitful areas for further research.

Kristin H. Gerhard is Catalog Librarian/Associate Professor in Parks Library at Iowa State University; email: kgerhard@iastate.edu. Mila C. Su is Associate Librarian/Reference Coordinator in the Robert E. Eiche Library at Pennsylvania State University; e-mail: mcs@psulias.psu.edu. Charlotte C. Rubens is Head of Interlibrary Services in the University of California Berkeley Library at the University of California-Berkeley; e-mail crubens@library.berkeley.edu. In addition to the three authors, seven other librarians participated in planning this study, collecting data, and discussing the raw results. They were: Shelley Almgren, Oklahoma Panhandle State University; Daren Callahan, Southern Illinois University; Anne Moore, Boston College; Susanne Nevin, St. Olaf College; G. Margaret Porter, University of Notre Dame; Françoise Puniello, Rutgers University; and Debbie Tenofsky, University of Illinois at Chicago. 


\section{Literature Review}

Three major areas addressed in the literature contribute to concerns about subject access in women's studies: subject heading terminology, the nature of interdisciplinary studies, and the cataloging process.

\section{Subject Heading Terminology}

The terminology chosen for Library of Congress Subject Headings (LCSH) is the most immediately obvious source of subject access problems. More than one author has pointed out sexist language and limited concepts reflected in the LCSH. ${ }^{1}$ Sanford Berman's book on LC subject headings for people documents sexism throughout LCSH; Joan K. Marshall's On Equal Terms documented extensive problems with subject headings about women. ${ }^{2-3}$ According to Judith Hudson and Victoria A. Mills, ALCSH reflects a white male bias in its representation of the world: Men are the norm and women, the exception. The fact that LCSH contains sexist and biased terminology has troubled many librarians for years. ${ }^{4}$

Another problem with LCSH terminology is that precise subject headings may be lacking. Hudson and Mills note that, "[b]ecause the Library of Congress is often slow to add or change subject headings relating to women, the terminology used to provide subject analysis is often neither current nor specific. ${ }^{5}$ Hope Olson, on examining a sample of 100 bibliographic records, finds that almost 50 percent of the sample has less than useful headings; she describes LCSH as "weak in addressing women-centered research topics." 6

\section{Interdisciplinary Nature of Women's Studies}

The interdisciplinary nature of women's studies complicates subject cataloging of its materials. Materials are assessed by catalogers in order to determine the primary subject area upon which both the classification and the first subject head- ing are based. In the case of interdisciplinary materials, this determination may result in assignment of overly broad subject headings. There is a further complication in the case of women's studies. Ellen Gay Detlefson raises the issue that women's studies material is not the same as material about women. ${ }^{7}$ Subject headings designed to describe material about women (generally discipline specific) may not be suitable to describe women's studies materials (generally interdisciplinary). Women's studies provides fundamentally new, integrative approaches to many established topics, but this is difficult to bring out when describing these materials using LCSH. Olson, for example, details four basic orientations of feminist research and notes specific deficiencies in the LCSH in describing each of the four categories. ${ }^{8}$

\section{In themselves, however, Boolean and key word searching do not solve access difficulties.}

Where multiple subject headings are available and appropriately assigned, technological advances with databases and online catalogs and the use of Boolean and key word searching have improved accessibility for women's studies materials. In themselves, however, Boolean and key word searching do not solve access difficulties. Loretta P. Koch and Barbara G. Preece refer to various discussions about the interdisciplinary nature of women's studies, pointing out that, too often, terms can be too broad for "meaningful searching." ${ }^{\prime 9}$ Cindy Faries and Patricia A. Scott highlight the problems:

Since the average user has neither the time nor the inclination to master the intricacies of Library of Congress Subject Headings, library staff must do so. To avoid the difficulties of subject searching, users often rely on poorly constructed keyword 
searches that result in a discouraging overabundance of hits. ${ }^{10}$

Although automation of catalogs has helped to improve access to resources, it does not remove the responsibility of those who provide or assign subject headings to be diligent in clearly identifying correct headings.

\section{The Cataloging Process}

The cataloging process raises several issues. First, subject headings assigned may not accurately or completely reflect the subject content of the item. This may be due to time constraints, cataloger unfamiliarity with the subject area, or failure to review pertinent information such as the introduction, preface, or table of contents. Many times, broad or inaccurate subject headings are assigned. Where appropriate subject headings exist, they may not be used as frequently as necessary to provide precise access. Olson highlights this in her evaluation of headings assigned to a hundred titles by the Library of Congress. Her first recommendation for improving access is that "the Library of Congress follow its own principle of specific entry and use its own subject headings to their fullest potential."11 Margaret N. Rogers points out that heading formulation is influenced, among other factors, by "the views of the selector who does the books the Library of Congress has in a given field."12 Some help is available to catalogers handling women's studies materials. In Women in LC's Terms, Ruth Dickstein, Victoria A. Mills, and Ellen J. Waite collected, reviewed, and organized "subject headings used for women and topics of relevance to women's lives."13 Their intent was to help meet the needs of both catalogers and researchers by identifying and gathering established LCSH terminology into one source.

Second, the heavy reliance of academic libraries on copy cataloging, while enhancing cataloging efficiency, means that any problems in the initial assignment of subject headings are likely to perpetuate themselves. The initially assigned subject headings may not reflect the subject of the material accurately. According to Olson, "virtually no library using widely accepted controlled vocabularies such as LCSH relies entirely on original cataloging. Most library cataloging comes from a shared source such as a bibliographic utility. Therefore, good subject access depends not only upon the standard system ( $\mathrm{LCSH})$, but also on the quality of cataloging copy contributed." 14 Because original cataloging is not used commonly, copy cataloging can perpetuate imprecise description. One cannot assume that cataloging copy will be rechecked in subsequent libraries for appropriateness or adequacy of subject headings.

Third, cataloging norms and standards suggest that each work be assigned a fairly limited number of subject headings. Susan E. Searing observes that this is more damaging to subject access in the long run than the limits of LCSH terminology. ${ }^{15}$ In her words,

Computerization makes it feasible to present many more access points by subject to a single book, yet library catalogs have not followed the lead of automated indexes and abstracts.

The reality of the library budget, rather than the bright potential of technology, defines the scope of the catalog. Excellent cataloging is labor intensive. It requires a firm grasp of the book's subject and knowledge of its potential readers. ${ }^{16}$

This is a practical approach from the point of view of cataloging management, given the kind of subject analysis needed by works in traditional disciplines. On the other hand, these norms may not serve interdisciplinary materials, which cover the intersections of ideas from multiple disciplines, as well as would be desired. 
Finally, a study by Elaine Svenonius and Dorothy McGarry hypothesized "that to a considerable degree [their italics] there is a clear-cut right and wrong to LCSH subject heading assignment."17 In their review of bibliographic records for a hundred items, they found that "true fuzziness" existed in very few cases, affecting only four items. "On the basis of this finding, it would seem that indeed objectivity in assessing subject heading assignment is feasible." 18 This suggests that evaluating subject headings in a large set of records would be a reasonable approach to assessing the state of subject access for women's studies materials.

\section{Research Questions}

The questions that remained for the authors of this study were: How poor or inadequate is subject access to women's studies materials, and to which factors can we assign the most weight? To investigate this in some depth, the authors proposed the following research questions:

1. What subject concepts present in the core women's studies literature are inadequately represented in the subject headings on OCLC records for these materials?

2. Which of these subject concepts could have been expressed adequately using LCSH?

3. Which of these subject concepts suggest the need for new main subject headings or subdivisions in the LCSH scheme?

4. Is there a set of recommended practices for practicing catalogers who catalog women's studies materials which could significantly improve access to these titles in the future?

\section{Methodology}

The methodology for this research was a systematic comparison of important works in women's studies to the subject headings they have been assigned. To develop a large enough data set to be meaningful, the com- mittee carried out this comparison by using annotations for the works rather than the works themselves. A standard list of central women's studies works was needed to serve as the source of the annotations. The committee selected Catherine Loeb, Susan E. Searing, and Esther Stineman's Women's Studies: ARecommended Core Bibliography, 1980-1985, second edition, a critical annotated bibliography covering most subject areas in women's studies. ${ }^{19}$

\section{Literary works were excluded because they tend not to be assigned subject headings.}

Following ALA's 1993 Annual Conference, the chair of the committee divided the bibliography by subject and assigned each committee member several sections based on interest and expertise. Literary works were excluded because they tend not to be assigned subject headings. Eventually, reference works and periodicals also were eliminated from the sample because they tend to be assigned broad headings rather than the more specific subject headings that were the object of the study.

OCLC was searched for each title listed and a bibliographic record identified. Library of Congress (DLC) records were preferred, but records contributed by member libraries were used when no DLC record was found. Only one title lacked OCLC copy and was dropped from the study. Subject headings in the record then were compared to the abstract in Loeb, Searing, and Stineman to determine whether the main concepts covered by each book were represented adequately.

To provide for consistent data collection, the committee developed a uniform data collection form (UDCF). The UDCF requested the following information for each range of citations investigated:

1. subject area;

2. entry numbers of annotations in Loeb, Searing, and Stineman; 


\begin{tabular}{|c|c|c|c|c|c|c|}
\hline \multicolumn{7}{|c|}{$\begin{array}{c}\text { TABLE } 1 \\
\text { UDCF Numerical Data Summary } \\
\end{array}$} \\
\hline \multirow[b]{2}{*}{$\underline{\text { Subject Area }}$} & \multirow[b]{2}{*}{$\mathrm{N}$} & \multirow[b]{2}{*}{$\begin{array}{l}\text { DLC } \\
\text { Copy }\end{array}$} & \multirow[b]{2}{*}{$\begin{array}{l}\text { Non-DLC } \\
\text { Copy }\end{array}$} & \multicolumn{3}{|c|}{$\begin{array}{c}\text { Concepts Absent or } \\
\text { Inadequately Representec }\end{array}$} \\
\hline & & & & $\mathrm{N}$ & $\begin{array}{l}\text { LCSH } \\
\text { Exists }\end{array}$ & $\begin{array}{c}\text { LCSH } \\
\text { Needed }\end{array}$ \\
\hline $\begin{array}{l}\text { Anthropology, cross-cultural } \\
\text { surveys, and international } \\
\text { surveys }\end{array}$ & 49 & 49 & 0 & 16 & 10 & 6 \\
\hline Art and material culture & 102 & 100 & 2 & 64 & 64 & 0 \\
\hline $\begin{array}{l}\text { Autobiography, biography, } \\
\text { diaries, memoirs, and } \\
\text { letters }\end{array}$ & 92 & 90 & 2 & 8 & 5 & 3 \\
\hline Business, economics, and labor & 48 & 48 & 0 & 20 & 6 & 14 \\
\hline Education and pedagogy & 27 & 25 & 2 & 9 & 2 & 7 \\
\hline History & 89 & 89 & 0 & 11 & 11 & 0 \\
\hline Language and linguistics & 10 & 9 & 1 & 7 & 5 & 2 \\
\hline Law & 22 & 22 & 0 & 9 & 4 & 5 \\
\hline Literature: History and criticism & 83 & 76 & 7 & 22 & 21 & 1 \\
\hline $\begin{array}{l}\text { Medicine, health, sexuality, } \\
\text { and biology }\end{array}$ & 31 & 30 & 1 & 16 & 4 & 12 \\
\hline Politics and political theory & 18 & 18 & 0 & 12 & 2 & 10 \\
\hline Psychology & 35 & 35 & 0 & 23 & 5 & 18 \\
\hline Religion and philosophy & 42 & 42 & 0 & 5 & 4 & 1 \\
\hline $\begin{array}{l}\text { Science, mathematics, } \\
\text { and technology }\end{array}$ & 17 & 17 & 0 & 6 & 3 & 3 \\
\hline Sociology and social issues & 71 & 69 & 2 & 27 & 17 & 10 \\
\hline Sports & 17 & 17 & 0 & 11 & 10 & 1 \\
\hline $\begin{array}{l}\text { Women's movement and } \\
\text { feminist theory }\end{array}$ & 73 & 65 & 8 & 16 & 9 & 7 \\
\hline Totals & 826 & 801 & 25 & 282 & 182 & 100 \\
\hline
\end{tabular}

3. number of entries for which DLC/ DLC records were located and used in analysis;

4. number of entries for which only a member library cataloging (non-DLC/ DLC) record was located and used in analysis;

5. any concepts relating to women's studies that were present in one or more annotation, but absent or inadequately represented in one or more of the cataloging records examined (list);

6. any LC subject headings or subdivisions corresponding to a missing concept in item 5 above which could have been (or could now be, if they are new) used if the cataloger had been aware of the headings and realized that they were appropriate (list);

7. any concepts listed in item 5 above that do not have a matching LC subject heading or subdivision, suggestions for LC-like subject headings or subdivisions for any concepts where LC subject headings are lacking currently (list);

8. any additional trends, observations, or areas for further investigation that arise in the research process.

In completing the UDCF, participants consulted both the Library of Congress Subject Headings and Subject Heading Manual, and Women in LC's Terms by Dickstein, 


\begin{tabular}{|l}
\multicolumn{1}{|c|}{ Table 2} \\
\multicolumn{1}{|c|}{ Sample Concepts Missing from } \\
\hline \hline Bibliographic Records \\
Asian American women \\
Battered woman syndrome \\
Clitoridectomy \\
Eating disorders \\
Feminist research methods \\
Feminization of poverty \\
Gender gap in politics \\
Gender identity \\
Gender-free science \\
History of the legal status of women \\
Images of women \\
Jewish women \\
Lesbians \\
Nontraditional students \\
Nonverbal communication and gender \\
Pioneer women \\
Premenstrual syndrome \\
Prochoice movement \\
Women and achievement \\
Women and depression \\
Women artists \\
Women in the labor movement \\
Women in the military \\
Women in World War I \\
Women political leaders \\
Women refugees \\
Women's health \\
Women's sexuality \\
\hline
\end{tabular}

Mills, and Waite for ideas on other headings that might be more accurate or useful. Information was compiled and submitted to the committee cochairs. The final lists generated in items 5, 6, and 7 above were reviewed to further increase consistency and accuracy in the data set.

\section{Study Results}

The numerical data compiled from the UDCFs is given in table 1 . Of the 826 citations used in the study, 801, or about 97 percent, had DLC/DLC copy in the OCLC union catalog. These records set the standard for cataloging in the United States and should represent the assignment of available subject headings. How- ever, there were many disturbing discoveries in these records. The subject heading problems that emerged seriously affect access to the materials. Citations were noted in every subject area that had one or more of the following problems:

1. Obsolete subject headings or subdivisions appeared in the cataloging record.

2. There was an absence of existing relevant subject headings or subdivisions in the cataloging record.

3. No relevant LC subject heading or subdivision was available.

4. Subject headings assigned in the cataloging record were too general.

5. Subject headings assigned in the cataloging record were too specific.

In every subject area, there were works for which entire major concepts had been either represented inadequately or not represented at all in the cataloging. This was the case approximately 30 percent of the time. The authors identified 282 concepts as inadequately represented or missing entirely. Most of the time, the missing concepts were not exotic but, rather, were the types of concepts a women's studies scholar would be looking for. A sample of the concepts that seemed important when reading the annotations, yet were not evident in the bibliographic records, is given in table 2 . In addition, there were many instances where aspects regarding race, nationality, religion, profession, gender, or sexual orientation were totally omitted, including concepts such as lesbian Christians, women anthropologists, Jewish women, and African women authors.

Understanding that LC subject headings and subdivisions have evolved during the decade since the second edition of Women's Studies: A Recommended Core Bibliography, 1980-1985 was published, the committee attempted to determine whether appropriate subject headings and subdivisions now exist which might have been used at the time of the original cataloging had the cataloger been aware of them. Although the participants did 


\begin{tabular}{|l}
\multicolumn{1}{c|}{ Table 3} \\
\multicolumn{1}{|c|}{$\begin{array}{c}\text { Sample of Existing Established LC } \\
\text { Subject Headings Lacking in } \\
\text { Bibliographic Records }\end{array}$} \\
\hline \hline Achievement motivation in women \\
Battered woman syndrome \\
Feminism and art \\
Feminist literary theory \\
Middle-aged women \\
Psychoanalysis and feminism \\
Women in trade unions \\
subdivision-Women under headings for \\
$\quad$ individual wars \\
Women-Employment \\
Women and war \\
Women athletes \\
Women authors, French \\
Women film critics \\
Women in motion pictures
\end{tabular}

not attempt a historical analysis of whether these specific subject headings existed at the time the titles were cataloged, the authors did identify existing subject headings in 182 cases which would be relevant for these titles but were not in the catalog record. Some of these subject headings are shown in table 3. This left a total of one hundred absent concepts that could not be expressed by LCSH. Some of these concepts are shown in table 4 .

\section{Discussion}

Through this study, the committee identified a large number of basic concepts that were either overlooked in cataloging or lacked an established subject heading at the time the item in question was cataloged. These concepts averaged out over the study sample to a little more than one in three records, which is a sizeable proportion.

Revisiting the authors' initial concerns about the impact of terminology, the nature of interdisciplinary fields, and the cataloging process, the results indicate definite and interrelated problems in all three areas. Multiple examples of every kind of problem were enumerated in the literature. The lack of established LCSH headings for basic women's studies concepts continues to be discouraging. One or two broad headings frequently were assigned to works when a greater number of more specific headings would have provided more appropriate access. As noted above, the cataloging process both contributes to and perpetuates this problem.

It is not news that the Library of Congress plays catchup in authorizing subject headings. A widely accepted concept may not receive an authorized subject heading for years. It was only in August of 1996 that LC replaced the heading "Man" with "Human beings." The works cited in Loeb, Searing, and Stineman generally were produced between 1980 and 1985, in most cases well into the era of recognizable feminist critical thought when women's concerns were being articulated and researched. Although there may be cases where automation has aided in changing outdated subject headings, it is generally a difficult task. In the case

\begin{tabular}{c} 
TABLE 4 \\
Sample of Concepts Lacking \\
Adequate Established \\
Subject Headings \\
\hline \hline
\end{tabular}

Depression in women

DES daughters

Female correspondance

Feminist nuns

Gender-free science

Lesbian authors

Segregation of women

Sex role socialization

Sports stories-Women

free-floating subdivision-Feminist approaches

free-floating subdivision-Feminist critiques pattern subdivision under individual names -Female influences

DES (Drug) (currently $x$-ref from

Diethylstilbestol)

Family law (currently $x$-reffrom Domestic relations)

PMS (currently x-ref from Premenstrual syndrome) 
of women's studies and feminism, it is not a viable solution because of the absence of relevant subject headings in the original cataloging.

Rogers comments on the gradual increase of subject headings added during the past decade and remarks that it is more efficient for LC to add new subject headings than to apply any retrospective adjustments. ${ }^{21}$ The concepts identified in this study were those found in core titles for a maturing interdisciplinary field. It is understandable that appropriate subject headings might not have existed at

\section{The lack of established LCSH headings for basic women's studies concepts continues to be discourag- ing.}

the time these works were published. The discouraging facts are that (1) where appropriate headings have been established after the fact, they have not been added to the relevant records; and (2) many of those headings have yet to be established today. This can be summed up in two serious questions for subject catalogers:

1. How do we avoid denying access to mature as well as to pioneering work in a field just because there were inadequate subject headings available at the time the work was issued?

2. How do we guarantee that works in a new and not necessarily widely accepted discipline will receive adequate subject access?

\section{Conclusions}

What should be done to improve the subject access provided to women's studies materials through LC subject headings? The committee recommends a threepronged approach, based on the deficiencies identified by this research. First, the many concepts for which no appropriate LC subject heading is available can be approached by submitting revised and suggested new headings to the Library of Congress for considerations. The literary warrant required by the library in order for a heading to be revised or established can be presented clearly by reference to the annotations in Loeb, Searing, and Stineman and their description of the core literature of women's studies. The committee has begun to assemble these submissions. Although the authors recognize that the Library of Congress establishes headings based on the works it catalogs rather than by the systematic analysis of intellectual concepts, area by area, the fact that these books had been cataloged by LC without the creation of adequate subject headings is disturbing. The Library of Congress would serve the cataloging community better by being more proactive in its creation and assignment of subject headings. Where LC does not perform analysis to interlink and interrelate subject headings in emerging fields, it may be advisable for catalogers and scholars to work together to accomplish this task, field by field.

Second, the lack of retrospective review of bibliographic records when new subject headings eventually are established confounds access to research materials. This warrants a serious reevaluation of cataloging policies that establish new headings without consideration of older works for which they would be appropriate. Materials in emerging fields are particularly hard hit by this phenomenon, and this should cause concern to those responsible for making the nation's research collections accessible to cuttingedge researchers.

Finally, it is clear from the results of this research that too few catalogers are aware of the range of subject headings already available for use, or of the necessity of bringing out the woman-centered or feminist aspects of a work in separate subject headings. The committee recommends the development of a brief catalogers' tool to aid those learning or practicing cataloging in subject analysis and subject heading assignment for women's studies and other interdisciplinary materials. 


\section{Notes}

1. These references are too numerous to give a complete listing. The discussion that follows includes representative examples.

2. Sanford Berman, Prejudices and Antipathies: A Tract on the LC Subject Heads Concerning People (Metuchen, N.J.: Scarecrow Pr., 1971).

3. Joan K. Marshall, On Equal Terms: A Thesaurus for Nonsexist Indexing and Cataloging (New York: Neal-Schuman, 1977).

4. Judith Hudson and Victoria A. Mills, "Women in the National Online Bibliographic Database," in Women Online, eds. Judith Hudson and Steven Atkinson (New York: Haworth, 1990), 245.

5. Ibid., 245.

6. Hope Olson, "Subject Access to Women's Studies Materials," in Cataloging Heresy: Challenging the Standard Bibliographic Product: Proceedings of the Congress for Librarians, February 18, 1991, ed. Bella Hass Weinberg (Medford, N.J.: Learned Information, 1992), 163.

7. Ellen Gay Detlefson, "Issues of Access to Information about Women," in Women's Collections: Libraries, Archives and Consciousness, ed. Suzanne Hildenbrand (New York: Haworth, 1986), 164.

8. Olson, "Subject Access to Women's Studies Materials," 162-65.

9. Loretta P. Koch and Barbara G. Preece, "Table of Contents Services: Retrieving Women's Studies Periodical Literature," RQ, 35 (fall 1995), 76-86.

10. Cindy Faries and Patricia A. Scott, "Invisible Collections within Women's Studies: Practical Suggestions for Access and Assessment," paper presented at the ACRL 7th Annual Conference, Pittsburgh, Penn., Mar. 31, 1995, 5.

11. Olson, "Subject Access to Women's Studies Materials," 166.

12. Margaret N. Rogers, "Are We on Equal Terms Yet? Subject Headings in LCSH, 1975-1991," Library Resources and Technical Services 37, no. 2 (Apr. 1993): 195.

13. Ruth Dickstein, Victoria A. Mills, and Ellen J. Waite, Women in LC's Terms: A Thesaurus of Library of Congress Subject Headings Relating to Women (Phoenix, Ariz.: Oryx Pr., 1988).

14. Olson, "Subject Access to Women's Studies Materials," 165.

15. Susan E. Searing, "How Libraries Cope with Interdisciplinarity: The Case of Women's Studies," Issues in Integrative Studies, no. 10 (1992): 13.

16. Ibid.

17. Elaine Svenonius and Dorothy McGarry, "Objectivity in Evaluating Subject Heading Assignment," Cataloging \& Classification Quarterly 16, no. 2 (1993): 7.

18. Ibid., 16.

19. Catherine Loeb, Susan E. Searing, and Esther Stineman, Women's Studies: A Recommended Core Bibliography, 1980-1985, 2nd ed. (Littleton, CO: Libraries Unlimited, 1987).

20. Library of Congress Subject Headings (Washington D.C.: Library of Congress, annual). Subject Heading Manual, 5th ed. (Washington, D.C.: Library of Congress, 1996).

21. Rogers, "Are We on Equal Terms Yet?" 195. 